\title{
Longitudinal Influence of Shared Marital Power on Marital Quality and Attachment Security
}

\author{
Nathan D. Leonhardt \\ University of Toronto \\ Brian J. Willoughby \\ Brigham Young University - Provo \\ W. Justin Dyer \\ Brigham Young University - Provo \\ Jason S. Carroll \\ Brigham Young University - Provo, jcarroll@byu.edu
}

Follow this and additional works at: https://scholarsarchive.byu.edu/facpub

Part of the Other Social and Behavioral Sciences Commons

\section{Original Publication Citation}

Leonhardt, N.D.*, Willoughby, B. J., Dyer, W. J., \& Carroll, J. S. (2019). Longitudinal Influence of Shared Marital Power on Marital Quality and Attachment Security. Journal of Family Psychology, $34,1-11$.

\section{BYU ScholarsArchive Citation}

Leonhardt, Nathan D.; Willoughby, Brian J.; Dyer, W. Justin; and Carroll, Jason S., "Longitudinal Influence of Shared Marital Power on Marital Quality and Attachment Security" (2019). Faculty Publications. 4371. https://scholarsarchive.byu.edu/facpub/4371

This Peer-Reviewed Article is brought to you for free and open access by BYU ScholarsArchive. It has been accepted for inclusion in Faculty Publications by an authorized administrator of BYU ScholarsArchive. For more information, please contact ellen_amatangelo@byu.edu. 


\title{
Longitudinal Influence of Shared Marital Power on Marital Quality and Attachment Security
}

\author{
Nathan D. Leonhardt \\ University of Toronto
}

\author{
Brian J. Willoughby, W. Justin Dyer, \\ and Jason S. Carroll \\ Brigham Young University
}

\begin{abstract}
Spouses perceiving that they have shared power in marriage has been linked to higher marital quality and attachment security. Existing research, however, is limited in assessing how these perceptions influence both spouses and whether these influences endure over time. To address these limitations, we analyzed the longitudinal relationship reports from 319 couples from the Flourishing Families Project (FFP) to estimate biyearly (Waves 1,3, and 5) and yearly (Waves 3-5) longitudinal actor-partner interdependence models. Reporting shared power in marriage was linked to the actors' higher marital quality and lower attachment insecurity over time (although less consistently for attachment insecurity). Longitudinal partner effects and indirect effects were also found from reports of shared marital power on both marital quality and attachment insecurity over time. The combined evidence suggests that power dynamics in a marriage are an important predictor of changes in couples' overall relational well-being. Accordingly, marriages appear to benefit from husbands and wives mutually seeking to help each other feel empowered in a relationship as equal and full partners.
\end{abstract}

Keywords: marital power, marital quality, attachment security, marriage

Supplemental materials: http://dx.doi.org/10.1037/fam0000566.supp

Perception of power, often considered the level of influence someone feels over another person (Cromwell \& Olson, 1975), is considered a basic force in social relationships (Keltner, Gruenfeld, \& Anderson, 2003). Based on a variety of social cues and hierarchies, we consciously and unconsciously assess our level of power in relation to those around us, engaging in a reciprocal process of external perception and internal regulation (Keltner et al., 2003). Some researchers have focused on power's social influence on broad dyadic interactions (e.g., Moreland \& Levine, 1989), with a growing body of work assessing perceived power specifically within marriage relationships (e.g., Byrne, Carr, \&

This article was published Online First August 8, 2019.

Nathan D. Leonhardt, Department of Psychology, University of Toronto; Brian J. Willoughby, School of Family Life, Brigham Young University; W. Justin Dyer, Department of Religious Education, Brigham Young University; Jason S. Carroll, School of Family Life, Brigham Young University.

We thank the Family Studies Center at Brigham Young University (BYU), the School of Family Life, and the College of Family, Home, and Social Sciences at BYU, and recognize the generous support of the many private donors who provided assistance for this project. We also thank those families who were willing to spend valuable hours with our team in interviews and the many students who assisted in conducting the interviews. Portions of this article were presented at the International Association for Relationship Research conference in 2018.

Correspondence concerning this article should be addressed to Nathan D. Leonhardt, Department of Psychology, University of Toronto, 3359 Mississauga Road, Toronto, ON L5LIC6, Canada. E-mail: nathan .leonhardt@mail.utoronto.ca
Clark, 2004; LeBaron, Miller, \& Yorgason, 2014). Reporting a power discrepancy in marriage (in these cases, perceiving a partner to have more control or influence in the relationship) has been connected to salient outcomes such as lower marital quality (LeBaron et al., 2014) and higher attachment insecurity (Oka, Brown, \& Miller, 2016).

However, a sizable percentage of empirical articles on perceived marital power have suffered from limitations such as small at-risk samples (e.g., Byrne et al., 2004), cross-sectional community samples (e.g., Brezsnyak \& Whisman, 2004), or only the wives' perspective (e.g., Bulanda, 2011). Furthermore, limited research has examined whether the perception of marital power dynamics has a longitudinal influence on relational outcomes (for an exception, see LeBaron et al., 2014), or how both spouses' perceptions play a role in both spouses' outcomes (for an exception, see Oka et al., 2016). To address these shortcomings, we utilized data from middle-aged, heterosexual married couples over five years of marriage to evaluate the longitudinal influence of marital power dynamics on marital quality and attachment insecurity.

\section{Marital Quality and Attachment Security}

Depression (Roberson, Lenger, Norona, \& Olmstead, 2018), life satisfaction, (Roberson et al., 2018), negative attributions (Karney \& Bradbury, 2000), personality (Robins, Caspi, \& Moffitt, 2000), relational aggression (Coyne et al., 2017), and caregiving (Mikulincer \& Shaver, 2016) are notable longitudinal predictors of relationship quality, but we know little about the predictive utility of power dynamics. Power dynamics could potentially influence marital quality, as power dynamics have been linked to these 
aforementioned longitudinal predictors such as relational aggression (Oka et al., 2016) and depression (Byrne et al., 2004). More broadly, both partners feeling empowered seems connected to engaging in relational practices (e.g., high caregiving) that promote well-being for both the self and the spouse (e.g., Gottman, 2011; Greenberg \& Goldman, 2008), whereas a sense of power discrepancy in marriage is typically connected to maladaptive practices (e.g., higher aggression) that undermine the relationship (e.g., Byrne et al., 2004; Mikulincer \& Shaver, 2016; Oka et al., 2016). This idea is also supported by attachment theory, suggesting that couples become communally oriented to each other by gradually developing trust through reliable responsiveness and alleviation of distress during troubled times (Mikulincer \& Shaver, 2016; Shaver \& Mikulincer, 2012).

Attachment theory, once focused primarily upon the attachment of a child to a caregiver (Ainsworth, Blehar, Waters, \& Wall, 1978), has become a staple theory in adult close relationships (Mikulincer \& Shaver, 2016). Although evidence has mounted that early childhood experiences have a lasting influence on adult attachment security, research has grown showing variability in adult attachment based on experience with a romantic partner (Fraley, 2002; Mikulincer \& Shaver, 2016). For example, one study found that trust toward a partner was uniquely associated with reduced attachment avoidance over time and perceived goal validation uniquely predicted reduced attachment anxiety over time (Arriaga, Kumashiro, Finkel, VanderDrift, \& Luchies, 2014). Currently, the consensus of the literature seems to be that attachment anxiety should decline in situations that foster greater personal confidence and more secure mental models of the self; attachment avoidance should decline most in situations that involve positive dependence and fostering more secure models of close others (Arriaga, Kumashiro, Simpson, \& Overall, 2018). As shared power implies a healthy sense of interdependence, it could provide the type of environment that fosters a secure mental model of both the self and the close other. This suggests that shared power could alleviate both attachment anxiety and attachment avoidance, resulting in an overall benefit for interpersonal security (Clark, von Culin, \& Hirsch, 2015).

\section{Relational Empowerment: Interdependence and Partner Effects}

More abstractly, interdependence theory (Rusbult \& Van Lange, 2008; Thibaut \& Kelley, 1978) offers an explanation for how reporting shared marital power could result in both actor and partner effects in promoting marital quality and attachment security. Some view marriage as a type of dominance hierarchy, with one partner seeking to obtain a power advantage over the other (Brown \& Lewis, 2004). This perspective seems embedded in ideas of competition and individualism, which link closely to social exchange theory (Thibaut \& Kelley, 1978). This lens may make sense among business associates or casual acquaintances, or even in the formation stages of a romantic relationship (Beck \& Clark, 2010), as individuals use a variety of strategies to selfempower in an attempt to gain relational, material, or sexual favors (Buss, 2017). However, research more clearly supports that an equal distribution of power, rather than a power discrepancy, is linked to optimal marital health (Gray-Little \& Burks, 1983). Some have suggested that a major reason for the benefits of a more equal distribution of power is the interdependent, communal nature of a marriage (Beck \& Clark, 2010). Once individuals have the long-term expectations of marital commitment, they seem to increase the likelihood of a union accompanied by a sense of permanence to the relationship (Willoughby \& James, 2017), a noncontingent concern for a spouse's welfare (Beck \& Clark, 2010), and a mindset of interdependence rather than exchange. Genuinely caring for a spouse and viewing the couple as a unit rather than two competing individuals likely yields benefits to both partners when they see the other as having equal importance and influence in the relationship.

One reason this sense of shared power might yield reciprocal benefits for both the individual and partner is through shared vulnerability (an authentic display of hopes, fears, and needs). Through shared vulnerability, opportunities are presented for each partner to respond to the other's needs and reliably alleviate distress, potentially increasing attachment security and marital quality over time (Mikulincer \& Shaver, 2016). A partner who feels she or he has more power is afraid of displaying vulnerability because it would show weakness; a partner who perceives himself of herself to be powerless is afraid of displaying vulnerability for fear of upsetting the partner (Beck \& Clark, 2010; KnudsonMartin, 2013). In connection with this idea, multiple reviews have suggested that when both partners feel relationally empowered and mutual support, the couple is more likely to have a relationship filled with vulnerability, as well as empathy, teamwork, and care (see Fishbane, 2011 and Knudson-Martin, 2013 for a more comprehensive review of the research). Altogether, relationships built upon shared power seem to lead to a healthy level of vulnerability that promotes empathy, teamwork, and care, thus potentially leading to reciprocal benefits in marital quality and attachment security for both the self and the spouse (e.g., Fishbane, 2011; Gottman, 2011; Greenberg \& Goldman, 2008; Mikulincer \& Shaver, 2016).

\section{Gender Considerations}

Gender is an important consideration when evaluating these associations. Some scholars argue that women's smaller physical stature and lower social hierarchy (e.g., gaps in earning power and education) construct marriage in a way that oppresses and subordinates women (Fisher \& Sharp, 2004; Wanic \& Kulik, 2011). Some research supports the idea of power gaps being particularly problematic for women, as the gap can lead to an inequality of decision making, double standards regarding sexual behavior, a higher risk for wives being victims of interpersonal violence, higher rates of depression, and lower marital happiness (e.g., Byrne et al., 2004; Finlay \& Clarke, 2003). Husbands' sense of powerlessness, however, should still be considered, as wives can also use a variety of tactics to gain power over their husband (e.g., displaying contempt; Fishbane, 2011). In fact, one review of power in marriage suggested that the husband feeling powerless was more problematic for the overall relationship than the wife feeling powerless (Gray-Little \& Burks, 1983). Perhaps husbands' sense of powerlessness can be particularly problematic due to feeling an inability to live up to society's expectation of him being the head of the household (Fisher \& Sharp, 2004; Wanic \& Kulik, 2011). Overall, research suggests that gender can play a role in understanding marriage power dynamics, with spouses having equal 
partnership having the happiest marriages (Kim, Visserman, \& Impett, 2019).

\section{Current Study}

To explore these issues, we performed cross-lagged analyses on middle-aged couples in a stable, marital relationship. Recent research has highlighted the value of assessing changes in the marital processes, even for couples who have been married for an extended period (Anderson, Van Ryzin, \& Doherty, 2010; Coyne et al., 2017; Mikulincer \& Shaver, 2016). After many years of marriage, couples can still engage in practices that either hurt or improve their marital quality (Coyne et al., 2017) and attachment security (Mikulincer \& Shaver, 2016). In these long-term marriages, much remains to be learned about the problematic nature of feeling a power discrepancy in a marriage, as opposed to feeling shared influence. For example, the lack of longitudinal evidence makes it difficult to ascertain the extent that feeling shared power in marriage is simply a byproduct of overarching relational and individual factors, or if shared power in marriage is predictive of change in outcomes over time.

Some limited cross-sectional studies have evaluated the association between perceived marital power and marital quality (Brezsnyak \& Whisman, 2004; Bulanda, 2011). One attempted to assess directionality, as a longitudinal study (LeBaron et al., 2014) showed no directional influence of wives' perception of power (the extent they reported equal partnership or their husband having more power over them) and marital happiness. The study was a helpful starting point, but their limited statistical power (67 participants) and 15-year lag between marital quality measures likely made it difficult to detect a direct longitudinal effect. This is because the quality of a marriage can change drastically over the period of 15 years (Anderson et al., 2010), and several unaccounted-for factors over such a long period may confluence results (Little, 2013). In summary, although one previous study failed to find a longitudinal link between perceived marital power and marital quality, a connection may be found with higher statistical power and shorter longitudinal intervals. Considering the importance of both partners reporting equal influence in the relationship (Fishbane, 2011; Gray-Little \& Burks, 1983), we hypothesized (H1) that both husbands' and wives' higher perception of shared power in the marriage will have a positive longitudinal actor and partner effect on both partners' marital quality.

Little research has considered perception of marital power and attachment insecurity. The two constructs have been shown to be significantly correlated (e.g., Oka et al., 2016), as feeling a partner has more influence in the relationship is associated with feeling an insecure attachment. Conceptually, this study only considered the possibility of attachment being a predictor of perceived marital power, and not the inverse. However, considering a growing body of research suggesting that relational experiences can influence attachment insecurity over time (Shaver \& Mikulincer, 2012), and that feeling mutual influence in marriage seems to validate each other's worth (Greenberg \& Goldman, 2008), we hypothesized (H2) that both husbands' and wives' higher perception of shared power in the relationship will have a negative longitudinal actor and partner effect on both partners' attachment insecurity. For the sake of parsimony, and theoretical reasoning suggesting that shared power should similarly influence attachment anxiety and attachment avoidance, we conceptualized attachment insecurity as an overall level of interpersonal insecurity in the relationship (e.g., Clark et al., 2015; Oka et al., 2016), combining items from anxious and avoidant attachment subscales. ${ }^{1}$

In assessing the longitudinal associations of these constructs, we also assessed bidirectionality, a possibility for any of our constructs of interest. For example, lower marital quality and higher attachment insecurity could each lead to reporting lower shared power in the marriage. Individuals with these characteristics may be more likely to misinterpret benign actions or intentions of their partner as malevolent, and thus a threat to their sense of power in the relationship (Shaver \& Mikulincer, 2012). Considering the possibility of various well-being outcomes coloring the perception of the relationship (Shaver \& Mikulincer, 2012), we therefore hypothesized (H3) that the relationship between marital power and our chosen outcomes will be bidirectional. Finally, because gender has been shown to be an important consideration for marital power research in the past, we broadly asked, to what extent are results similar by gender (RQ1)?

H1: Husbands' and wives' higher perception of shared power in the relationship will have a positive directional actor and partner effect on both partners' marital quality.

H2: Wives' and husbands' higher perception of shared power in the relationship will have a negative directional actor and partner effect on both partners' attachment insecurity.

H3: The relationship between perceived marital power and our chosen outcomes will be bidirectional.

$R Q 1$ : To what extent are the results similar by gender?

\section{Method}

\section{Participants and Procedure}

Participants were selected from a large northwestern city in the United States and were interviewed once a year for 5 years (2007-2011). Families were primarily recruited using Polk Directories/InfoUSA that describes the presence and age of children in each household. Families identified using this directory were randomly selected from targeted census tracts that mirrored the socioeconomic and racial stratification of reports of local school districts. All families with a child between the ages of 10 and 14 living within target census tracts were deemed eligible to participate in the Flourishing Families Project (FFP). Of the 692 eligible families contacted, 423 agreed to participate (61\% response rate). Families of lower socioeconomic status were slightly underrepresented by using this technique. Therefore, in an attempt to more closely mirror the demographics of the local area, a limited number of families were recruited into the study through other means (e.g.,

\footnotetext{
${ }^{1}$ To ensure that collapsing anxious and avoidant attachment into one construct was not problematic, we conducted supplemental analyses with the two constructs separate. These analyses are shown in Figure S2, Figure S3, and Table S5. As these analyses suggested a similar story to the more parsimonious analyses, the more parsimonious analyses are included in the manuscript.
} 
referrals, fliers; $n=77,15 \%$, for a total $N=500$ ). The study was approved by the institutional review board (IRB).

All questionnaires were screened for missing answers and double marking. The final sample for the current study consists of parents only that were drawn from the FFP study's first five waves of assessment (total $n=500$ families, comprising 337 two-parent families and 163 single-parent families at Wave 1). Only married couples who had complete data over the 5 years were included in the current analysis. Thirteen couples reported cohabiting at Wave 1 , and these were excluded from the analysis. Over the course of 5 years, nine couples divorced, three separated, and two were widowed.

At Wave 5, the final sample consisted of 319 couples $(94.7 \%$ retention from Wave 1). The average age of husbands in the sample was 45.39 years $(S D=5.97)$ at Wave 1 , and the average age of wives was 43.44 years $(S D=5.42)$ at Wave 1 . At Wave 1 , the average length of time in the current relationship was 17.85 years $(S D=5.21)$. Additionally, $75 \%$ of families were of European American ethnicity and $4.2 \%$ were African American, with smaller numbers for Hispanics (0.3\%) and Asian Americans $(1.2 \%)$. Nineteen percent of families were considered multiethnic in nature, based on a combination of two or more ethnic cultures among family members. In terms of parental education, $72 \%$ of women and $69 \%$ of men had a bachelor's degree or higher. For income, $14 \%$ made less than $\$ 25,000$ per year, $16 \%$ made between $\$ 25,000$ and $\$ 50,000$ a year, and $70 \%$ made more than $\$ 50,000$ per year, with $21 \%$ of two-parent mothers and $5 \%$ of two-parent fathers reporting being unemployed.

We briefly note that although data were collected for the couples across five years of marriage (2007-2011), Wave 2 (2008) was not usable for our particular analysis because the participants did not answer questions about attachment insecurity. For that reason, we utilized Waves 1 and 3-5 for our analyses. We explain our data analysis plan in further detail below.

\section{Measures}

Marital power. For this study, the Marital Power Index was used, which asks respondents to report on her or his perception of their partner's displays of power in the relationship (Bogue, Miller, \& Day, 2008; LeBaron et al., 2014; Oka et al., 2016). Items were coded as a continuum from one partner perceiving the other partner to have greater influence than oneself in the relationship (lower scores) to one partner perceiving the relationship to have more of a shared power (higher scores). Items were based on a 5-point Likert-type scale (e.g., "My partner and I talk about problems until we both agree on a solution"). Marital power had high reliability at all four waves, with Cronbach's alphas between .92 and .93 for husbands, and between .91 and .93 for wives. Items were originally created as separate subscales for power outcomes and power processes (Bogue et al., 2008), but these subscales were collapsed for this study as their distinction was not critical to our research aims. All items for our power measure are listed in the online supplemental materials (Table S1).

Marital quality. Marital quality was assessed using a 5-item modified version of the Quality Marriage Index (Norton, 1983). The responses were based on a 6-point Likert scale (e.g., "My relationship with my partner makes me happy") ranging from 1 (very strongly disagree) to 6 (very strongly agree). Higher scores indicated higher perceived marital quality. Marital quality had acceptable reliability at all four waves, with Cronbach's alphas between .97 and .98 for wives, and between .96 and .97 for husbands.

Attachment insecurity. Attachment insecurity was measured using the Experiences in Close Relationships scale (ECR; Brennan, Clark, \& Shaver, 1998). The ECR is a measure designed to examine dimensions of insecure attachment, including subscales of avoidance and anxiety. Eight items from the revised version were used for this study (four items each from attachment avoidance and attachment anxiety subscales), including items such as "I am afraid that I will lose my partner's love." All items are listed in the online supplemental materials (Table S2). Items were based on a 7-point Likert scale ranging from 1 (strongly disagree) to 7 (strongly agree). Items were summed to obtain a combined anxiety and attachment score for each partner and coded so that the higher on the scale indicated higher overall attachment insecurity. Attachment insecurity had acceptable reliability at all four waves, with Cronbach's alphas between .83 and .87 for husbands, and between .84 and .89 for wives.

Control variables. We utilized several control variables that have been found to relate to power (Keltner et al., 2003), attachment insecurity (Mikulincer \& Shaver, 2016), and marital quality (Bradbury \& Karney, 2010). Education was assessed by asking both wives and husbands to report on their highest completed grade/level in school on a 7-point Likert scale, with response options ranging from 1 (less than high school) to 7 (advanced degree). Income was assessed by asking both husbands and wives to each report their individual annual income, ranging from 1 (under $\$ 10,000$ per year) to 12 ( $\$ 200,000$ or more per year). ${ }^{2}$ Both respondent's age and race (dummy coded, with white as the comparison variable) and the wife's report of the length of the marital relationship were also used as controls. Neuroticism (Stricker \& Rock, 1998), measured at Wave 2, was also used as a control variable for both wives and husbands, as it has been found to be a longitudinal predictor of relationship quality (Robins et al., 2000). Participants were asked to report on a scale from 1 (not at all applicable to me) to 7 (completely applies to me) the extent they were irritable, nervous, touchy, anxious, fearful, and highstrung. The six items had acceptable reliability, with a Cronbach's alpha of .75 for husbands and .80 for wives.

\section{Results}

\section{Data Analysis Plan}

Means and standard deviations for all main variables are found in Table 1. We tested for mean differences between wives and husbands on each of the variables of interest across time. We also tested correlations between all study variables. Only variables from Wave 1 and Wave 3 are shown in Table 2. Throughout the results section, we use abbreviations for the main constructs of interest to help with readability (e.g., Wave 1 Husbands' Report of Shared Marital Power $=$ HP1; Wave 4 Wives' Attachment Inse-

\footnotetext{
${ }^{2}$ Supplementary analyses were conducted throughout the study on income discrepancy to see if the variable added anything different than both spouses' reports of their own income. Like the income variables, income discrepancy showed little association with any of our constructs of interest (full results available upon request).
} 
Table 1

Descriptive Statistics and Gender Differences

\begin{tabular}{|c|c|c|c|c|c|c|c|c|c|c|}
\hline \multirow[b]{2}{*}{ Variable } & \multicolumn{4}{|c|}{ Husbands } & \multicolumn{4}{|c|}{ Wives } & \multirow{2}{*}{$\begin{array}{l}\text { Response } \\
\text { range }\end{array}$} & \multirow[b]{2}{*}{$t$ values } \\
\hline & $M$ & $S D$ & $\alpha$ & Skew & $M$ & $S D$ & $\alpha$ & Skew & & \\
\hline \multicolumn{11}{|l|}{ Shared power } \\
\hline Wave 1 & 3.74 & .66 & .92 & -.65 & 4.05 & .63 & .91 & -.65 & $1-5$ & $7.51^{\text {***** }}$ \\
\hline Wave 3 & 3.77 & .69 & .93 & -.61 & 4.06 & .64 & .92 & -.69 & $1-5$ & $6.58^{* * * *}$ \\
\hline Wave 4 & 3.72 & .70 & .92 & -.68 & 4.01 & .68 & .92 & -.69 & $1-5$ & $6.61^{* * * *}$ \\
\hline Wave 5 & 3.71 & .73 & .93 & -.51 & 3.96 & .72 & .93 & -.68 & $1-5$ & $5.77^{\text {***** }}$ \\
\hline \multicolumn{11}{|l|}{ Marital quality } \\
\hline Wave 1 & 5.18 & .91 & .96 & -1.46 & 5.15 & .06 & .97 & -1.33 & $1-6$ & .49 \\
\hline Wave 3 & 4.96 & 1.00 & .97 & -1.31 & 4.91 & 1.15 & .98 & -1.11 & $1-6$ & .53 \\
\hline Wave 4 & 4.91 & .98 & .97 & -1.02 & 4.80 & 1.10 & .97 & -.95 & $1-6$ & 1.82 \\
\hline Wave 5 & 4.85 & 1.02 & .97 & -.88 & 4.77 & 1.09 & .97 & -.90 & $1-6$ & .94 \\
\hline \multicolumn{11}{|l|}{ Attachment insecurity } \\
\hline Wave 1 & 2.27 & 1.04 & .84 & 1.04 & 2.05 & .99 & .84 & 1.11 & $1-7$ & $3.79^{* * * *}$ \\
\hline Wave 3 & 2.32 & 1.04 & .85 & 1.05 & 2.21 & 1.08 & .84 & 1.10 & $1-7$ & 1.64 \\
\hline Wave 4 & 2.39 & .06 & .83 & .84 & 2.25 & 1.12 & .89 & 1.01 & $1-7$ & $2.26^{*}$ \\
\hline Wave 5 & 2.41 & 1.13 & .87 & .93 & 2.29 & 1.17 & .88 & 1.08 & $1-7$ & 1.97 \\
\hline \multicolumn{11}{|l|}{ Controls } \\
\hline Age & 45.39 & 5.97 & - & 1.71 & 43.44 & 5.42 & - & -.13 & $27-62$ & $7.55^{* * * *}$ \\
\hline Race (Minority) & .12 & .33 & - & 2.33 & .19 & .39 & - & 1.61 & $0-1$ & $-2.93^{*}$ \\
\hline Education & 4.89 & 1.49 & - & -.07 & 4.69 & 1.40 & - & -.46 & $1-7$ & $2.07^{*}$ \\
\hline Income & 5.99 & 2.32 & - & 83 & 3.52 & 2.28 & - & 1.11 & $1-12$ & $12.91^{* * * * *}$ \\
\hline Relationship length & - & - & - & - & 17.85 & 5.21 & - & .20 & $2-40$ & - \\
\hline Neuroticism & 3.25 & .98 & .75 & .27 & 3.45 & 1.06 & .80 & -.19 & $1-6$ & $-2.85^{* *}$ \\
\hline
\end{tabular}

Note. Relationship length does not have values for husbands because only the wives' report was used in analyses.

${ }^{*} p<.05 .{ }^{* *} p<.01 .^{* * * *} p<.001$.

curity $=$ WI4). The codes for abbreviations are listed beneath Table 2 and Table 3.

We used cross-lagged models to examine whether either spouse's perception of marital power has a directional influence on both spouses' marital quality and attachment insecurity (see Figure $\mathrm{S} 1$ in the online supplemental materials for a description of all pathways). Considering the limited longitudinal research on perceived marital power, it was unclear whether the influence of marital power is best captured by assessing yearly or biyearly intervals between waves of data. It may be a salient predictor of outcomes for more short-term intervals, or its effects may only be made manifest over a longer passage of time. Furthermore, Wave
2 of the study was not usable because participants did not answer questions about attachment insecurity. For these reasons, we decided to create multiple cross-lagged models: one with yearly intervals, and one with biyearly intervals. The first model consisted of Waves 1,3 , and 5 to assess whether perceived marital power has a directional influence on our outcomes of interest at a biyearly interval (see Figure 1). The second model consisted of Waves 3-5, to assess the directional influence of perceived marital power at yearly intervals (see Figure 2). By having models with both yearly and biyearly intervals, if the models are consistent with each other, it can increase confidence in the longitudinal associations. Meanwhile, if inconsistencies are found between the two

Table 2

Bivariate Correlations

\begin{tabular}{|c|c|c|c|c|c|c|c|c|c|c|c|c|}
\hline Variable & 1 & 2 & 3 & 4 & 5 & 6 & 7 & 8 & 9 & 10 & 11 & 12 \\
\hline 1. Shared power 1 & $.42^{*}$ & $.51^{*}$ & $-.58^{*}$ & $.72^{*}$ & $.42^{*}$ & $-.48^{*}$ & .01 & .05 & $.14^{*}$ & -.00 & .00 & $-.18^{*}$ \\
\hline 2. Marital quality 1 & $.63^{*}$ & $.51^{*}$ & $-.55^{*}$ & $.41^{*}$ & $.48^{*}$ & $-.46^{*}$ & -.06 & .08 & .02 & .05 & -.01 & $-.18^{*}$ \\
\hline 3. Attachment insecurity 1 & $-.61^{*}$ & $-.59^{*}$ & $.42^{*}$ & $-.44^{*}$ & $-.41^{*}$ & $.59^{*}$ & .02 & -.03 & .01 & -.04 & .04 & $.16^{*}$ \\
\hline 4. Shared power 3 & $.74^{*}$ & $.55^{*}$ & $-.49^{*}$ & $.55^{*}$ & $.53^{*}$ & $-.63^{*}$ & .03 & -.04 & $.18^{*}$ & .02 & .05 & -.09 \\
\hline 5. Marital quality 3 & $.53^{*}$ & $.62^{*}$ & $-.48^{*}$ & $.60^{*}$ & $.42^{*}$ & $-.56^{*}$ & .03 & .09 & .05 & .05 & -.06 & -.05 \\
\hline 6. Attachment insecurity 3 & $-.57^{*}$ & $-.58 *$ & $.59^{*}$ & $-.72^{*}$ & $-.66^{*}$ & $.56^{*}$ & .03 & -.04 & -.02 & .03 & .10 & $.12^{*}$ \\
\hline 7. Age & -.02 & -.04 & -.00 & .10 & .01 & -.04 & $.73^{*}$ & $-.18^{*}$ & $.34^{*}$ & $.17^{*}$ & $.52^{*}$ & -.08 \\
\hline 8. Race (Minority) & -.05 & .03 & .02 & -.11 & .01 & .02 & -.09 & - & $-.14^{*}$ & .01 & $-.11^{*}$ & -.07 \\
\hline 9. Education & .09 & .03 & -.06 & $.15^{*}$ & .10 & -.01 & $.14^{*}$ & $-.13^{*}$ & $.46^{*}$ & $.17^{*}$ & $.13^{*}$ & .10 \\
\hline 10. Income & .11 & $.16^{*}$ & -.10 & .10 & $.19^{*}$ & -.08 & -.00 & $-.13^{*}$ & $.35^{*}$ & .01 & .11 & -.02 \\
\hline 11. Length & .08 & -.01 & .02 & .06 & .03 & .06 & $.45^{*}$ & $-.12^{*}$ & $.16^{*}$ & $.15^{*}$ & - & -.04 \\
\hline 12. Neuroticism & $-.22^{*}$ & $-.28^{*}$ & $.19^{*}$ & $-.23^{*}$ & $-.21^{*}$ & $.31^{*}$ & -.06 & -.06 & -.05 & -.08 & -.03 & $.16^{*}$ \\
\hline
\end{tabular}

Note. Wives' correlations are above the diagonal. Husbands' correlations are below the diagonal. The bolded diagonal is the intercorrelation between husbands and wives. The intercorrelation for race is precluded due to problems with correlating two dichotomous variables. The intercorrelation for relationship length is precluded as only the wife's report was used. Numbers following abbreviations indicate the wave that was used. $* p<.05$. 
Table 3

All Significant Indirect Effects From Both SEM Models

\begin{tabular}{|c|c|c|c|c|c|}
\hline Waves $1,3,5$ & $\beta$ & $S E$ & Waves $3-5$ & $\beta$ & $S E$ \\
\hline IE on Shared power & & & IE on Shared power & & \\
\hline $\mathrm{HP} 1 \rightarrow \mathrm{HP} 3 \rightarrow \mathrm{HP} 5$ & $.48^{* * * *}$ & .05 & $\mathrm{HP} 3 \rightarrow \mathrm{HP} 4 \rightarrow \mathrm{HP} 5$ & $.35^{* * * *}$ & .06 \\
\hline $\mathrm{HP} 1 \rightarrow \mathrm{WP} 3 \rightarrow \mathrm{WP} 5$ & $.15^{* * * *}$ & .04 & WP3 $\rightarrow$ WP4 $\rightarrow$ WP5 & $.41^{* * * *}$ & .05 \\
\hline $\mathrm{WP} 1 \rightarrow \mathrm{WP} 3 \rightarrow \mathrm{WP} 5$ & $.45^{* * *}$ & .05 & $\mathrm{WI} 3 \rightarrow \mathrm{WP} 4 \rightarrow$ WP5 & $-.07^{*}$ & .05 \\
\hline IE on Marital quality & & & IE on Marital quality & & \\
\hline $\mathrm{HP} 1 \rightarrow \mathrm{WP} 3 \rightarrow \mathrm{HQ} 5$ & $.03^{*}$ & .02 & $\mathrm{HP} 3 \rightarrow \mathrm{HP} 4 \rightarrow \mathrm{HQ} 5$ & $.11^{* * *}$ & .04 \\
\hline $\mathrm{HP} 1 \rightarrow \mathrm{HP} 3 \rightarrow \mathrm{HQ} 5$ & $.11^{* * *}$ & .05 & $\mathrm{HP} 3 \rightarrow \mathrm{HQ} 4 \rightarrow \mathrm{HQ} 5$ & $.12^{* * *}$ & .05 \\
\hline $\mathrm{HP} 1 \rightarrow \mathrm{HQ} 3 \rightarrow \mathrm{HQ} 5$ & $.06^{*}$ & .03 & $\mathrm{WP} 3 \rightarrow \mathrm{WP} 4 \rightarrow \mathrm{HQ} 5$ & $.07^{*}$ & .03 \\
\hline $\mathrm{WP} 1 \rightarrow \mathrm{WP} 3 \rightarrow \mathrm{HQ} 5$ & $.08^{*}$ & .04 & $\mathrm{HQ} 3 \rightarrow \mathrm{HQ} 4 \rightarrow \mathrm{HQ} 5$ & $.17^{* * * *}$ & .04 \\
\hline $\mathrm{HP} 1 \rightarrow \mathrm{WP} 3 \rightarrow$ WQ5 & $.05^{*}$ & .02 & $\mathrm{HP} 3 \rightarrow \mathrm{HP} 4 \rightarrow \mathrm{WQ} 5$ & $.11^{*}$ & .06 \\
\hline \multirow[t]{2}{*}{ WP1 $\rightarrow$ WP3 $\rightarrow$ WQ5 } & $.14^{* *}$ & .04 & HP3 $\rightarrow$ HQ4 $\rightarrow$ WQ5 & $.05^{*}$ & .03 \\
\hline & & & WP3 $\rightarrow$ WP4 $\rightarrow$ WQ5 & $.09^{*}$ & .04 \\
\hline IE on Attachment insecurity & & & $\mathrm{HQ} 3 \rightarrow \mathrm{HQ} 4 \rightarrow \mathrm{WQ} 5$ & $.07^{*}$ & .03 \\
\hline $\mathrm{HP} 1 \rightarrow \mathrm{HI} 3 \rightarrow \mathrm{HI} 5$ & $-.18^{* * * *}$ & .04 & & & \\
\hline $\mathrm{HI} 1 \rightarrow \mathrm{HI} 3 \rightarrow \mathrm{HI} 5$ & $.14^{* * * * *}$ & .04 & IE on Attachment insecurity & & \\
\hline $\mathrm{WP} 1 \rightarrow \mathrm{WI} 3 \rightarrow$ WI5 & $-.09^{* * *}$ & .04 & $\mathrm{HP} 3 \rightarrow \mathrm{HI} 4 \rightarrow \mathrm{HI} 5$ & $-.10^{* *}$ & .03 \\
\hline $\mathrm{WI} 1 \rightarrow$ WI3 $\rightarrow$ WI5 & $.22^{* * * *}$ & .05 & $\mathrm{HI} 3 \rightarrow \mathrm{HI} 4 \rightarrow \mathrm{HI} 5$ & $.24^{* * * *}$ & .06 \\
\hline \multirow[t]{2}{*}{$\mathrm{HP} 1 \rightarrow \mathrm{HP} 3 \rightarrow$ WI5 } & $-.11^{*}$ & .05 & HP3 $\rightarrow$ WI4 $\rightarrow$ WI5 & $-.05^{*}$ & .03 \\
\hline & & & $\mathrm{WI} 3 \rightarrow \mathrm{WI} 4 \rightarrow \mathrm{WI} 5$ & $.24^{* * * * *}$ & .07 \\
\hline
\end{tabular}

Note. $\mathrm{H}=$ husband; $\mathrm{W}=$ wife; $p=$ shared marital power; $\mathrm{I}=$ attachment insecurity; $\mathrm{Q}=$ marital quality; $\mathrm{IE}=$ indirect effect. Numbers following abbreviations indicate the Wave that was used.

${ }^{*} p<.05$. $^{* * *} p<.01$. $^{* * * *} p<.001$.

models, it can provide insight into the appropriate length of lag needed to detect effects of and on perceived marital power (Little, 2013). Although not the primary focus of the study, we also tested bidirectionality by assessing whether both spouses' marital quality and attachment insecurity have a directional influence on wives' and husbands' perceptions of marital power.

Ideally, it would be advantageous to create latent variables for each of the constructs of interest for the SEM models. Unfortu-

Wave 1

$\underline{\text { Wave } 3}$

Wave 5

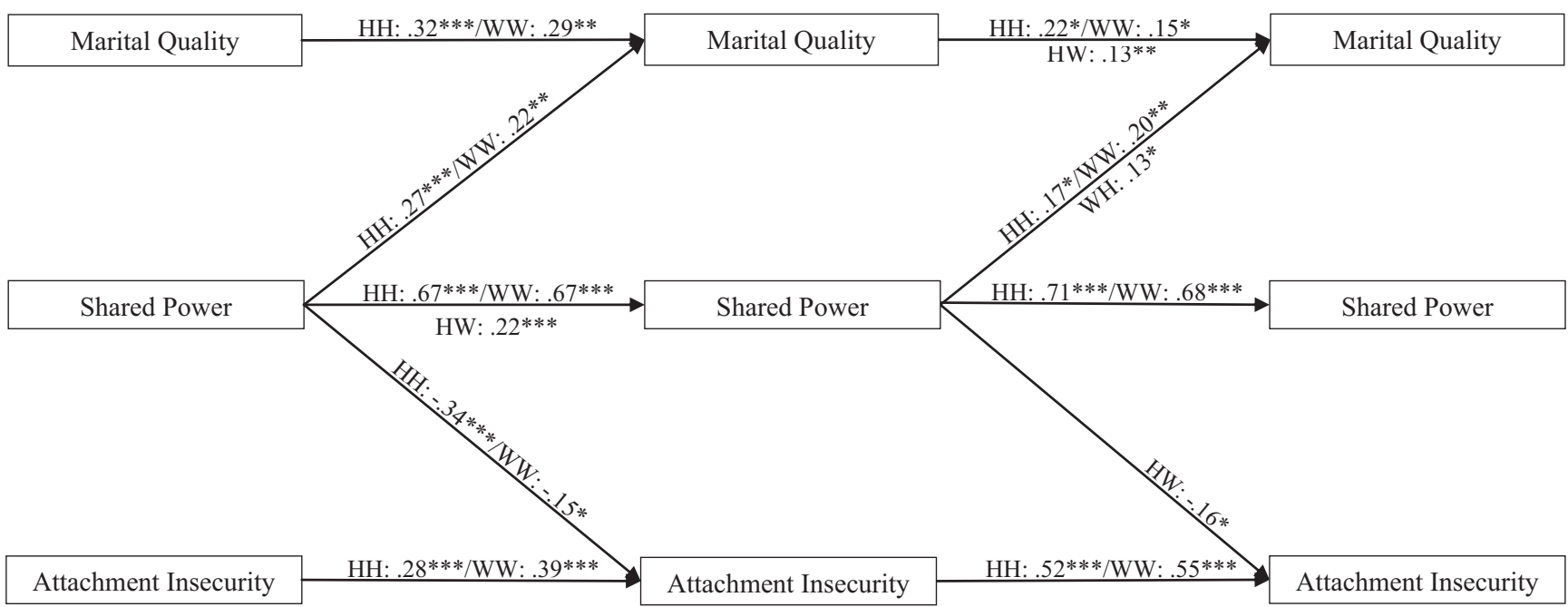

Figure 1. Cross-lagged model of shared marital power, marital quality, and attachment insecurity for Waves 1,3 , and 5. Chi-square $(50)=163.15, p<.001, \mathrm{CFI}=.97, \mathrm{RMSEA}=.08, \mathrm{SRMR}=.03$. Nonsignificant paths, endogenous error correlations, and AR2 pathways (HQ1-HQ5; WQ1-WQ5) are omitted from the figure for the sake of parsimony. Analyses controlled for wives' report of marital length, and both spouses' age, race, education, and income at each wave. $\mathrm{HH}=$ actor coefficient for husbands; $\mathrm{WW}=$ actor coefficient for wives; $\mathrm{HW}=$ partner coefficient for husbands' influence on wives; $\mathrm{WH}=$ partner coefficient for wives' influence on husbands. All coefficients are standardized beta values. ${ }^{*} p<.05$. ${ }^{* * *} p<.01$. $^{* * * *} p<.001$. 


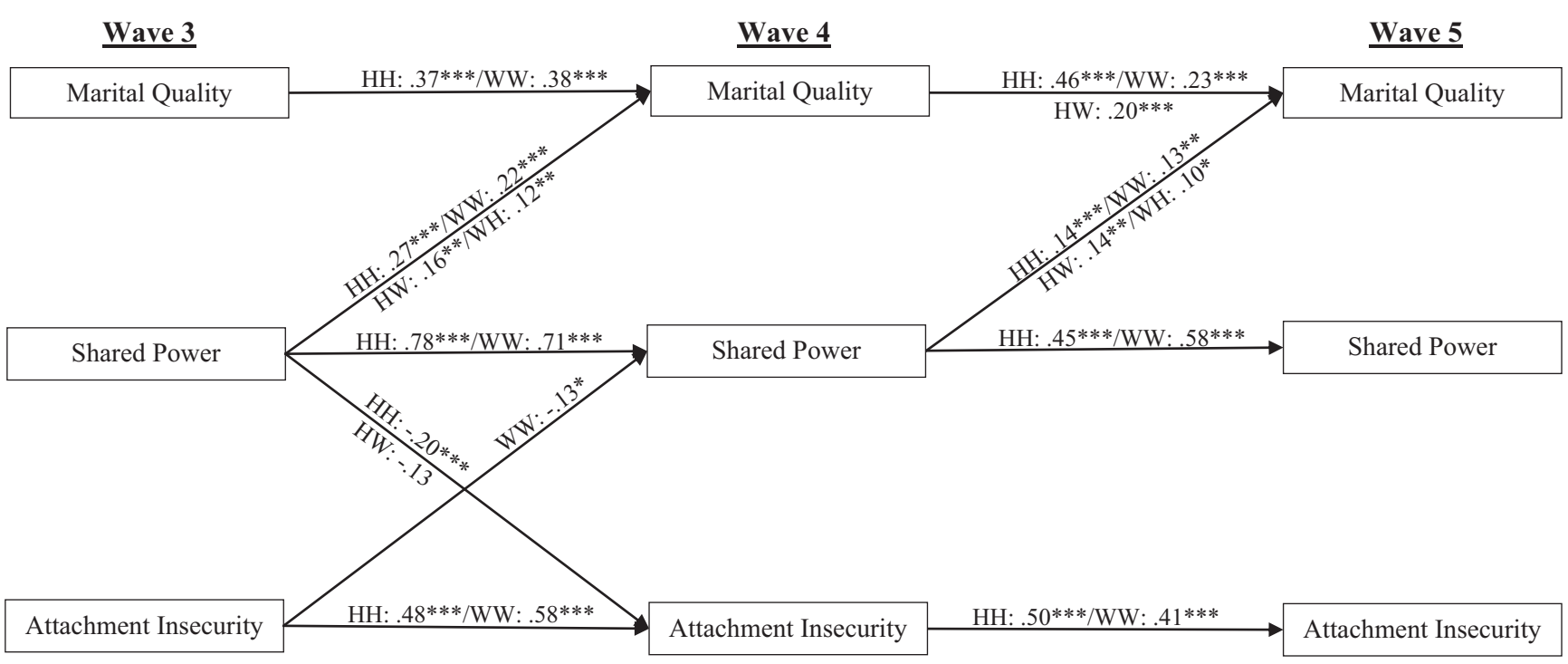

Figure 2. Cross-lagged model of shared marital power, marital quality, and attachment insecurity for Waves $3-5$. Chi-square $(46)=79.58, p<.001, \mathrm{CFI}=.99$, RMSEA $=.50$, SRMR $=.02$. Nonsignificant paths, endogenous error correlations, and AR2 pathways (HI3-HI5; WI3-WI5; HP3-HP5; WP3-WP5; HQ3-HQ5; WQ3-WQ5) are omitted from the figure for the sake of parsimony. Analyses controlled for wives' report of marital length, and both spouses' age, race, education, income, and neuroticism at each wave. $\mathrm{HH}=$ actor coefficient for husbands; WW = actor coefficient for wives; HW = partner coefficient for husbands' influence on wives; $\mathrm{WH}=$ partner coefficient for wives' influence on husbands. All coefficients are standardized beta values. ${ }^{*} p<.05 .{ }^{* *} p<.01 .{ }^{* * *} p<.001$.

nately, the sample did not have sufficient power to utilize latent variables for each construct. To help account for some of the measurement error, we instead created factor scores for each of the constructs. Based on the suggestion that there should be 10 cases for every observed variable (Kline, 2016), we created a total of 12 measurement models, each with husbands and wives modeled simultaneously, when obtaining factor scores (e.g., HP1 and WP1; HI1 and WI1; HQ1 and WQ1). For example, because the construct for marital power had 15 items, we modeled latent variables for wives and husbands ( 30 total items; within the parameters recommended by Kline) and obtained their factor scores. After obtaining factor scores for each construct, we created the most parsimonious model possible by first entering only the stability coefficients, cross-lagged patterns, and control variables. Afterward, we used modification indices and theoretical reasoning to add necessary AR2 pathways (Little, 2013), in order to obtain acceptable model fit $($ CFI $>.90$ and RMSEA $<.08$; Browne \& Cudeck, 1993; Kline, 2016).

Finally, we checked for any indirect effects in the model for all variables of interest with 5000 bootstraps. With the complexity of each model yielding over 200 unique indirect effects, it would be impractical to list them all. Instead, we briefly summarized the significant indirect effects of note in our results section, and created a table showing each significant indirect effect (see Table 3).

\section{Preliminary Analyses}

Using paired sample $t$ tests, we explored gender differences for all the variables. Table 1 shows means, standard deviations, Cron- bach's alphas (if applicable), response ranges, and $t$ values of each variable. We also tested correlations among all study variables. For readability, only Wave 1 and Wave 3 variables are shown in Table 2. More detailed correlations are shown in Table S4 in the online supplemental materials. For our main variables of interest, intercorrelations between husbands and wives ranged from .4 to .6. This is the typical level of intercorrelation that reflects the uniqueness of each variable while also being tied to the partner's report (e.g., Kenny, Kashy, \& Cook, 2006). We also assessed multicollinearity. The highest Variance Inflation Factor (VIF) at any wave was 2.85. Considering that the general rule of thumb is a VIF of greater than 10 being problematic (Kutner, Nachtsheim, \& Neter, 2004), with a more stringent cutoff of 5 commonly being used (Sheather, 2009), we felt that our constructs were well within the parameters of avoiding multicollinearity.

\section{Measurement Models}

As mentioned, 12 separate measurement models, each with constructs for husbands and wives modeled simultaneously (e.g., HP1 and WP1), were estimated to obtain factor scores for the main constructs of interest (perceived marital power, attachment insecurity, and marital quality). Each of the 12 models had adequate model fit (Kline, 2016), as the CFI of each model was .93 or higher and the RMSEA was .08 or lower. Factor scores were extracted and the scales were utilized as observed variables in the SEM models. In the measurement models we also found that wives and husbands failed to reach strong invariance for shared power and attachment insecurity, meaning we could not directly assess differences in structural paths (Dyer, 2015; Little, 2013). 
Full results on measurement invariance are available in supplemental Table S3.

\section{Structural Equation Models}

Waves 1, 3, 5. The model for Waves 1,3, and 5 fit the data well (chi-square $(50)=163.15, p<.001, \mathrm{CFI}=.97, \mathrm{RMSEA}=$ .08$, SRMR $=.03)$. In order to achieve this adequate model fit, the model required AR2 pathways from HQ1 $\rightarrow$ HQ5 and WQ1 $\rightarrow$ WQ5. These pathways were based on having the highest modification index values (Kline, 2016; Little, 2013). The variables explained a moderate level of variance for each dependent variable $(\mathrm{WP3}=.57$; HP3 = .59; WP5 = .55; HP5 = .62; WQ3 = .31; $\mathrm{HQ} 3=.41 ; \mathrm{WQ} 5=.48 ; \mathrm{HQ} 5=.56$; WI3 = .42; HI3 = .46; $\mathrm{WI} 5=.50 ; \mathrm{HI} 5=.45$ ).

The most consistent influence was actor effects of perceiving shared power in the marriage. Husbands' reports of shared power were consistently associated his own higher marital quality $(\mathrm{HP} 1 \rightarrow \mathrm{HQ} 3: \beta=.27, p<.001 ; \mathrm{HP} 3 \rightarrow \mathrm{HQ} 5: \beta=.17, p=.02)$, and wives' reports of shared power were consistently associated with her own higher marital quality (WP1 $\rightarrow$ WQ3: $\beta=.22, p<$ .01 ; WP3 $\rightarrow$ WQ5: $\beta=.20, p<.01)$. There also was some evidence of actor effects from husbands' report of shared power on attachment insecurity from Wave 1 to Wave 3 (HP1 $\rightarrow$ HI3: $\beta=-.34, p<.001$ ), but not from Wave 3 to Wave 5 (HP3 $\rightarrow$ HI5: $\beta=-.07, p=.35$ ). Similarly, wives' report of shared power was associated with her own report of attachment insecurity from Wave 1 to Wave 3 (WP1 $\rightarrow$ WI3: $\beta=-.16, p=.01$ ), but not from Wave 3 to Wave 5 (WP3 $\rightarrow$ WI5: $\beta=-.08, p=.21$ ). Some evidence of partner effects was found, as wives' report of shared power was related to husbands' higher marital quality from Wave 3 to Wave 5 (WP3 $\rightarrow$ HQ5: $\beta=.13, p=.02$ ). Also, husbands' report of shared power was related to lower wives' attachment insecurity from Wave 3 to Wave 5 (HP3 $\rightarrow$ WI5: $\beta=-.16, p=$ $.02)$. There was no evidence of bidirectionality. The only significant associations with controls are as follows: (Husband income $\rightarrow$ HQ3: $\beta=.11, p=.04$; Wife age $\rightarrow$ WQ3: $\beta=.22, p=.02$; Wife race $\rightarrow$ WQ3: $\beta=.09, p=.04$; Marital Length $\rightarrow$ WQ3: $\beta=-.13, p=.03$; Marital Length $\rightarrow$ HI3: $\beta=.13, p<.01$; Marital Length $\rightarrow$ WI3: $\beta=-.12, p=.03$; Marital Length $\rightarrow$ WP3: $\beta=-.11, p=.01$; Marital Length $\rightarrow$ HP3: $\beta=-.09, p=$ .04 ; Husband Neuroticism $\rightarrow$ HI3: $\beta=.17, p<.001$; Husband Income $\rightarrow$ HI5: $\beta=-.10, p<.01$ ). See Figure 1 for full results of outcomes of interest (including stability coefficients).

Waves 3-5. The model for Waves 3-5 also fit the data well (chi-square $(46)=79.58, p<.001, \mathrm{CFI}=.99, \mathrm{RMSEA}=.05$, SRMR $=.02)$. In order to achieve this adequate model fit, the model required the following AR2 pathways: HP3 $\rightarrow$ HP5, $\mathrm{WP} 3 \rightarrow \mathrm{WP} 5, \mathrm{HI} 3 \rightarrow \mathrm{HI} 5, \mathrm{WI} 3 \rightarrow \mathrm{WI}$, HQ3 $\rightarrow$ HQ5, and WQ3 $\rightarrow$ WQ5. The variables explained a moderate level of variance $\left(R^{2}\right)$ for each dependent variable $(\mathrm{WP} 4=.65$; HP4 $=.64$; $\mathrm{WP} 5=.68 ; \mathrm{HP} 5=.72 ; \mathrm{WQ} 4=.47 ; \mathrm{HQ} 4=.51 ; \mathrm{WQ} 5=.50$; $\mathrm{HQ} 5=.63$; WI4 $=.60 ; \mathrm{HI} 4=.54$; WI5 $=.61$; HI5 $=.57$ ).

Again, the most consistent influence was actor effects of reporting shared power in the marriage. Husbands' reports of shared marital power were consistently associated with their own higher marital quality $(\mathrm{HP} 3 \rightarrow \mathrm{HQ} 4: \beta=.27, p<.01$; HP4 $\rightarrow$ HQ5: $\beta=$ $.14, p<.01$ ), and wives' reports of shared power was consistently associated with their own higher marital quality (WP3 $\rightarrow$ WQ4: $\beta=.23, p<.01 ; \mathrm{WP} 4 \rightarrow$ WQ5: $\beta=.13, p=.03$ ). There also was some evidence of actor effects from husbands' report of shared power to attachment insecurity from Wave 3 to Wave 4 (HP3 $\rightarrow$ HI4: $\beta=-.20, p<.01$ ) but not from Wave 4 to Wave 5 (HP4 $\rightarrow$ HI5: $\beta=-.01, p=.85)$. Wives' report of shared power was not associated with her own report of attachment insecurity (WP3 $\rightarrow$ WI4: $\beta=-.10, p=.15$; WP4 $\rightarrow$ WI5: $\beta=-.11, p=.07)$. Some evidence of partner effects was found, as husbands' report of shared power was related to higher wives' marital quality at both waves $(\mathrm{HP} 3 \rightarrow$ WQ4: $\beta=.16, p<.01$; HP4 $\rightarrow$ WQ5: $\beta=.14$, $p<.05)$. Wives' report of shared power was also related to husbands' higher marital quality at both waves (WP3 $\rightarrow$ HQ4: $\beta=$ $.12, p<.05$; WP4 $\rightarrow$ HQ5: $\beta=.09, p=.04)$. Finally, husbands' report of shared power was related to lower wives' attachment insecurity from Wave 3 to Wave 4 (HP3 $\rightarrow$ WI4: $\beta=-.13, p=$ $.03)$. The only evidence of bidirectionality was a small association of wives' higher attachment insecurity being linked to wives' lower report of shared power from Wave 3 to Wave 4 (WI3 $\rightarrow$ WP4: $\beta=-.13, p=.03$ ). The only significant associations with controls were as follows: (Husband Income $\rightarrow$ HI4: $\beta=-10, p=$ .02 ; Husband Age $\rightarrow$ WI4: $\beta=-.11, p<.05$; Wife Age $\rightarrow$ WP4: $\beta=.11, p=.04$; Husband Age $\rightarrow$ WP4: $\beta=-.12, p=.02$; Wife Income $\rightarrow$ HQ5: $\beta=.09, p=.01$; Husband Education $\rightarrow$ WI5: $\beta=-.10, p=.02$; Husband Neuroticism $\rightarrow$ WQ4: $\beta=.11, p=$ .02 ). See Figure 2 for full model results (including stability coefficients).

Indirect effects. Perhaps the most noteworthy findings are that reports of shared power at the beginning wave of both models had significant indirect actor effects on higher marital quality for husbands and wives as well as lower attachment insecurity for wives and husbands (only in the biyearly model for wives). Also of note were some partner effects, such as husbands' report of shared power being related to higher marital quality for their wives as well as lower attachment insecurity for their wives. Attachment insecurity and marital quality from either spouse had no indirect effect on either spouse's report of shared power. Overall, these results suggest that reporting shared power has a directional influence on the actor, and a somewhat less clear directional influence on the partner. Significant indirect effects are shown in Table 3.

\section{Discussion}

The results provide evidence that perception of marital power plays a role in relational well-being over time. The most consistent finding across each wave of both structural models was that spouses' personal report of shared power in the relationship was related to their reporting a higher quality marriage in subsequent years. This was shown both directly and indirectly, as the first wave of reporting higher shared power influenced marital quality through a variety of pathways over the years. This finding is consistent with previous findings suggesting an association between marital power and marital quality (Brezsnyak \& Whisman, 2004; Bulanda, 2011), although it contrasts a previous study suggesting no directional influence from perceiving a power discrepancy in a marriage to marital quality over time (LeBaron et al., 2014). The contrast in these results is likely due in part to the previous study's comparatively small sample (67 participants), possibly giving the authors insufficient statistical power to detect a finding. 
Some evidence was found for other effects as well, as spouses' personal perception of shared power in the marriage was inconsistently linked to their own lower attachment insecurity in subsequent years. This lines up with previous theoretical (Shaver \& Mikulincer, 2012) and empirical (Oka et al., 2016) work suggesting that perception of power and attachment insecurity are intercorrelated, but adds to previous research by showing a directional association as well (albeit inconsistently). The inconsistency of this finding lacks easy explanation. Perhaps perception of power is simply less important for attachment insecurity than for marital quality. However, part of the explanation may be that actor effects predicting attachment insecurity were clearly the highest from Wave 1 to Wave 3, where the stability coefficients for attachment insecurity were also the lowest (Little, 2013). For some reason, it appears that attachment insecurity became more stable in later waves of this sample, giving it lower variance to be explained by perception of shared power. Also worth noting is that indirect effects existed for higher perception of shared power predicting attachment insecurity over time (i.e., HP1 $\rightarrow \mathrm{HI} 3 \rightarrow \mathrm{HI} 5$; WP1 $\rightarrow$ $\mathrm{WI} 3 \rightarrow \mathrm{WI} 5$; HP1 $\rightarrow$ HP3 $\rightarrow$ WI5; HP3 $\rightarrow$ HI4 $\rightarrow$ HI5; HP3 $\rightarrow$ WI4 $\rightarrow$ WI5). This could suggest that somewhat earlier patterns of power perception in the marriage can influence attachment insecurity both directly and indirectly into the future, although that influence tends to dwindle insofar as that attachment insecurity is stable.

This study also provides evidence that feeling shared power in the relationship may have a directional influence on the partner's marital quality and attachment insecurity. This supports previous cross-sectional research showing a connection between perceived shared power partner effects and attachment insecurity (Oka et al., 2016), but builds on it by adding a longitudinal component. Partner effects tended to be small and were somewhat inconsistent (e.g., few partner effects were found in the biyearly model). Yet the model for Waves 3-5 consistently showed that if one partner reported shared power in the relationship, their partner in the subsequent wave would report higher marital quality. The indirect effects also showed support for the possibility of partner effects; between the biyearly and yearly models there were five indirect partner effects on marital quality (i.e., WP1 $\rightarrow$ WP3 $\rightarrow$ HQ5; $\mathrm{HP} 1 \rightarrow \mathrm{WP} 3 \rightarrow \mathrm{WQ} 5 ; \mathrm{WP} 3 \rightarrow \mathrm{WP} 4 \rightarrow \mathrm{HQ} 5 ; \mathrm{HP} 3 \rightarrow \mathrm{HP} 4 \rightarrow$ WQ5; HP3 $\rightarrow$ HQ4 $\rightarrow$ WQ5) and two indirect partner effects on attachment insecurity (i.e., HP1 $\rightarrow$ HP3 $\rightarrow$ WI5; HP3 $\rightarrow$ WI4 $\rightarrow$ WI5).

Although partner effects were somewhat inconsistent, they provided evidence that there appears to be nothing beneficial in a partner believing she or he is subordinate in the marriage (Brown \& Lewis, 2004). Evidence supported the idea that it is beneficial for wives and husbands to both report a relationship of shared power, possibly signaling a joint pursuit of shared influence and equal partnership. This could support the recent theoretical assertion by Fishbane (2011), who suggested that true relational empowerment comes with a "power with" approach, where both spouses seek to mutually enable each other's sense of power. When it comes to power perception, marital power is not a single spectrum where one partner is vying for greater influence than the other (e.g., Fishbane, 2011; Knudson-Martin, 2013; Oka et al., 2016). Rather, each partner has her or his own perception of marital power, where one, both, or neither partner might feel empowered in the relationship. The ideal relationship seems built upon a feeling of mutual influence, rather than one or the other feeling that someone in the relationship has a higher level of power (Fishbane, 2011; Knudson-Martin, 2013).

Surprisingly, in the overall picture, little evidence was found for bidirectionality. In other words, the perception of power dynamics taking place in the relationship predicted changes in spouses' reports of marital quality and attachment insecurity, but marital quality and attachment insecurity did not predict changes in perception of power dynamics in the marriage. There was one theoretically plausible direct effect of wives' attachment insecurity on her own report of shared power in her relationship. This also appeared as a small indirect effect (WI3 $\rightarrow$ WP4 $\rightarrow$ WP5). Again, since attachment insecurity tends to color the lens through which individuals perceive their relationships (Shaver \& Mikulincer, 2012) it makes sense that someone who feels insecure in the relationship may be more likely to interpret certain actions by their partner as seizing power. In both models, one potential reason for the lack of bidirectionality was that perception of power had stronger stability coefficients than marital quality and attachment insecurity, meaning that there was less change to be predicted by alternative variables. Perhaps marital quality and attachment insecurity had less stability over time because they were based more on an affective state rather than processes occurring in the relationship. Additional research would be helpful in deepening confidence for whether there truly is a lack of bidirectionality between perceived marital power and the other main constructs. With correlational data, the possibility of unaccounted-for third variables (e.g., commitment, investment, perceived partner responsiveness, behaviors or affect) is also important to be considered.

\section{Limitations and Future Directions}

Although the study had strengths such as longitudinal data and using both partners' reports on the constructs, there were some limitations. One limitation is generalizability of these results. The study took place in one region of the United States, with middleaged couples in highly stable marriages. It would be worthwhile to gain a more representative sample to see whether these results replicate. It is interesting to note that perception of power appears to persist in its directional association even among couples in stable marriages. In this study, any prediction of change over time is likely a conservative estimate, as the dynamics within these longer-term relationships are relatively stable. This can be encouraging to couples who have been married for an extended period and may feel that their relationship is either declining or stagnant. Although it would likely be valuable to obtain a sample of younger couples to better understand when and how patterns of marital power might become more deeply entrenched in the marriage, it would also be valuable to obtain cross-cultural samples to assess how power dynamics play a role in marriage in regions with various levels of gender egalitarianism. Expectations surrounding shared partnership or dominance in the relationship might inform the extent someone is happy with sharing marital power as opposed to dominating or being dominated.

Some research has conceptualized both perception of power and attachment insecurity as multidimensional constructs. Based on differing research questions, it may make sense to evaluate specific aspects of each type of construct. Some research has suggested that the Marital Power Index can be broken down into subscales for 
processes and outcome (Bogue et al., 2008). While our research focus was less concerned with partialing out the influence of different aspects of marital power, other researchers may find that distinction applicable on the basis of their research question. For example, perhaps couple communication patterns might be more closely related to marital power processes than marital power outcomes. Also, it is important to consider that the measure of marital power focused on the degree to which someone felt a partner had more power in the relationship, as opposed to feeling shared influence. It could be interesting to explore the effect of someone feeling they have greater influence than their partner, to see whether that also is related to suboptimal outcomes.

There also may be some interesting questions to answer from the perspective of marital power outcomes research, particularly when it comes to gender-specific questions. Although items for perceiving a partner to have power in the domain of childcare or in the domain of finance may be under the overall umbrella of marital power research, some researchers may be interested in assessing whether differences exist in these domains. Particularly in light of traditional gender norms of husbands typically having greater responsibility over finances and wives typically having more responsibility with childcare, there may be some differences worth evaluating in these power domains (Wanic \& Kulik, 2011). For example, Tichenor (2005) has outlined domestic labor/childcare division, patterns of financial management, decision-making practices, and conflict resolution strategies as four domains of marital power. Considering that we failed to achieve measurement invariance between husbands and wives for the Marital Power Index, much remains to be explored about how women and men understand power as a construct. There may be qualitative differences in their understanding of power-oriented questions. Until this is better understood, we cannot make direct comparisons across mean scores. We cannot make direct comparisons between how a husband's perception of power differs from a wife's perception of power, because we do not understand the manner in which they are thinking about this power.

Furthermore, attachment insecurity can be broken down into measures for anxious and avoidant attachment (Mikulincer \& Shaver, 2016), although we did not do so in this particular study for the sake of parsimony. No major differences were found between evaluating overall attachment insecurity and breaking the construct into anxious and avoidant attachment (see online supplemental materials). Considering research has found differences in what alleviates anxious and avoidant attachment (e.g., Arriaga et al., 2014; Arriaga et al., 2018), future research should continue to explore in greater depth how dynamics of perceived marital power interrelate with these subdimensions of attachment insecurity.

Another possible future direction is to look at interactions between both spouses' reports of marital power. The combined evidence of actor effects and occasional partner effects suggests the benefits of both partners helping each other feel empowered in the relationship. However, this potentially synchronous pattern may be supported further by delving deeper into the interactions of both spouses' perception of marital power over time. It could also be beneficial to conduct person-level analyses, allowing statistics to identify specific couple types based on various power dynamics in a relationship and assess the longitudinal influence of those dynamics. Finally, it is important to note the limitation of relying solely on questionnaire data. Future research could benefit from more objective observation of power dynamics.

\section{Conclusion}

The results provide evidence that equal partnership, built upon a mutual degree of power, is a component for marital well-being over time. It appears that the ideal relationship is not where either wife or husband has greater power than her or his spouse (Fishbane, 2011; Knudson-Martin, 2013). Rather, both partners should be responsible for helping his or her spouse feel mutual influence in the relationship; both should feel their opinions are valid; both should be responsible for final decisions made.

\section{References}

Ainsworth, M. D. S., Blehar, M. C., Waters, E., \& Wall, S. (1978). Patterns of attachment: A psychological study of the strange situation. Hillsdale, NJ: Erlbaum.

Anderson, J. R., Van Ryzin, M. J., \& Doherty, W. J. (2010). Developmental trajectories of marital happiness in continuously married individuals: A group-based modeling approach. Journal of Family Psychology, 24, 587-596. http://dx.doi.org/10.1037/a0020928

Arriaga, X. B., Kumashiro, M., Finkel, E. J., VanderDrift, L. E., \& Luchies, L. B. (2014). Filling the void: Bolstering attachment security in committed relationships. Social Psychological and Personality Science, 5, 398-406. http://dx.doi.org/10.1177/1948550613509287

Arriaga, X. B., Kumashiro, M., Simpson, J. A., \& Overall, N. C. (2018). Revising working models across time: Relationship situations that enhance attachment security. Personality and Social Psychology Review, 22, 71-96. http://dx.doi.org/10.1177/1088868317705257

Beck, L. A., \& Clark, M. S. (2010). What constitutes a healthy communal marriage and why relationship stage matters. Journal of Family Theory \& Review, 2, 299-315. http://dx.doi.org/10.1111/j.1756-2589.2010 .00063.x

Bogue, A., Miller, R. B., \& Day, R. D. (2008). The development of a measure of couples relationship power. Poster presented at the Annual Conference of the American Association for Marriage and Family Therapy, Memphis, TN.

Bradbury, T. N., \& Karney, B. R. (2010). Intimate relationships. New York, NY: Norton.

Brennan, K. A., Clark, C. L., \& Shaver, P. R. (1998). Self-report measurement of adult attachment: An integrative overview. In J. A. Simpson \& W. S. Rholes (Eds.), Attachment theory and close relationships (pp. 46-76). New York, NY: Guilford Press.

Brezsnyak, M., \& Whisman, M. A. (2004). Sexual desire and relationship functioning: The effects of marital satisfaction and power. Journal of Sex \& Marital Therapy, 30, 199-217. http://dx.doi.org/10.1080/ 00926230490262393

Brown, S. L., \& Lewis, B. P. (2004). Relational dominance and mateselection criteria: Evidence that males attend to female dominance. Evolution and Human Behavior, 25, 406-415. http://dx.doi.org/10 .1016/j.evolhumbehav.2004.08.003

Browne, M. W., \& Cudeck, R. (1993). Alternative ways of assessing model fit. In K. A. Bollen \& J. S. Long (Eds.), Testing structural equation models (pp. 136-162). Newbury Park, CA: Sage.

Bulanda, J. R. (2011). Gender, marital power, and marital quality in later life. Journal of Women \& Aging, 23, 3-22. http://dx.doi.org/10.1080/ 08952841.2011 .540481

Buss, D. A. (2017). Sexual conflict in human mating. Current Directions in Psychological Science, 26, 307-313. http://dx.doi.org/10.1177/ 0963721417695559 
Byrne, M., Carr, A., \& Clark, M. (2004). Power in relationships of women with depression. Journal of Family Therapy, 26, 407-429. http://dx.doi .org/10.1111/j.1467-6427.2004.00291.x

Clark, M. S., Von Culin, K., \& Hirsch, J. (2015). Healthy and fragile interpersonal security: What we know and where we need to go. In P. J. Carroll, R. M. Arkin, \& A. L. Aaron (Eds.), Handbook of personal security (pp. 207-222). New York, NY: Psychology Press.

Coyne, S. M., Nelson, D. A., Carroll, J. S., Smith, N. J., Yang, C., Holmgren, H. G., \& Johnson, C. (2017). Relational aggression and marital quality: A five-year longitudinal study. Journal of Family Psychology, 31, 282-293. http://dx.doi.org/10.1037/fam0000274

Cromwell, R. F., \& Olson, D. H. (1975). Power in families. New York, NY: Wiley.

Dyer, W. J. (2015). The vital role of measurement equivalence in family research. Journal of Family Theory \& Review, 7, 415-431. http://dx.doi .org/10.1111/jftr.12115

Finlay, S. J., \& Clarke, V. (2003). “A marriage of convenience?" Feminist perspective on marriage. Feminism \& Psychology, 13, 415-420. http:// dx.doi.org/10.1177/09593535030134002

Fishbane, M. D. (2011). Facilitating relational empowerment in couple therapy. Family Process, 50, 337-352. http://dx.doi.org/10.1111/j.15455300.2011.01364.x

Fisher, E. A., \& Sharp, S. W. (2004). The art of managing everyday conflict: Understanding emotions and power struggles. Westport, CT: Praeger.

Fraley, R. C. (2002). Attachment stability from infancy to adulthood: Meta-analysis and dynamic modeling of developmental mechanisms. Personality and Social Psychology Review, 6, 123-151. http://dx.doi .org/10.1207/S15327957PSPR0602_03

Gottman, J. M. (2011). The science of trust: Emotional attunement for couples. New York, NY: Guilford Press.

Gray-Little, B., \& Burks, N. (1983). Power and satisfaction in marriage: A review and critique. Psychological Bulletin, 93, 513-538. http://dx.doi .org/10.1037/0033-2909.93.3.513

Greenberg, L. S., \& Goldman, R. N. (2008). Emotion-focused couples therapy: The dynamics of emotion, love, and power. Washington, DC: American Psychological Association. http://dx.doi.org/10.1037/11750000

Karney, B. R., \& Bradbury, T. N. (2000). Attributions in marriage: State or trait? A growth curve analysis. Journal of Personality and Social Psychology, 78, 295-309. http://dx.doi.org/10.1037/0022-3514.78.2.295

Keltner, D., Gruenfeld, D. H., \& Anderson, C. (2003). Power, approach, and inhibition. Psychological Review, 110, 265-284. http://dx.doi.org/ 10.1037/0033-295X.110.2.265

Kenny, D. A., Kashy, D. A., \& Cook, W. L. (2006). Dyadic data analysis. New York, NY: Guilford Press.

Kim, J. J., Visserman, M. L., \& Impett, E. A. (2019). Power in close intimate relationships. In C. R. Agney \& J. J. Harman (Eds.), Power in close relationship (pp. 192-224). New York, NY: Cambridge University Press. http://dx.doi.org/10.1017/9781108131490.010

Kline, R. B. (2016). Principles and practice of structural equation modeling. New York City, NY: Guilford Press.

Knudson-Martin, C. (2013). Why power matters: Creating a foundation of mutual support in couple relationships. Family Process, 52, 5-18. http:// dx.doi.org/10.1111/famp.12011

Kutner, M. H., Nachtsheim, C. J., \& Neter, J. (2004). Applied linear regression models (4th ed.). New York, NY: McGraw-Hill Irwin.
LeBaron, C. D. L., Miller, R. B., \& Yorgason, J. B. (2014). A longitudinal examination of women's perceptions of marital power and marital happiness in midlife marriages. Journal of Couple \& Relationship Therapy, 13, 93-113. http://dx.doi.org/10.1080/15332691.2013.852492

Little, T. D. (2013). Longitudinal structural equation modeling. New York, NY: Guilford Press.

Mikulincer, M., \& Shaver, P. R. (2016). Attachment in adulthood, second edition: Structure, dynamics, and change. New York, NY: Guilford Press.

Moreland, R. L., \& Levine, J. M. (1989). Newcomers and oldtimers in small groups. In P. Paulus (Ed.), Psychology of group influence (2nd ed., pp. 143-186). Hillsdale, NJ: Erlbaum.

Norton, R. (1983). Measuring marital quality: A critical look at the dependent variable. Journal of Marriage and the Family, 45, 141-151. http:// dx.doi.org/10.2307/351302

Oka, M., Brown, C. C., \& Miller, R. B. (2016). Attachment and relational aggression: Power as a mediating variable. The American Journal of Family Therapy, 44, 24-35. http://dx.doi.org/10.1080/01926187.2015 .1105716

Roberson, P. N. E., Lenger, K. A., Norona, J. C., \& Olmstead, S. B. (2018). A longitudinal examination of the directional effects between relationship quality and well-being for a national sample of U.S. men and women. Sex Roles, 78, 67-80. http://dx.doi.org/10.1007/s11199-017$0777-4$

Robins, R. W., Caspi, A., \& Moffitt, T. E. (2000). Two personalities, one relationship: Both partners' personality traits shape the quality of their relationship. Journal of Personality and Social Psychology, 79, 251259. http://dx.doi.org/10.1037/0022-3514.79.2.251

Rusbult, G. E., \& Van Lange, P. A. M. (2008). Why we need interdependence theory. Social and Personality Psychology Compass, 2, 20492070. http://dx.doi.org/10.1111/j.1751-9004.2008.00147.x

Shaver, P. R., \& Mikulincer, M. (2012). An attachment-theory framework for conceptualizing interpersonal behavior. In L. M. Horowitz \& S. Strack (Eds.), Handbook of interpersonal psychology: Theory, research, assessment, and therapeutic interventions (pp. 17-35). Hoboken, NJ: Wiley. http://dx.doi.org/10.1002/9781118001868.ch2

Sheather, S. (2009). A modern approach to regression with $R$. New York, NY: Springer. http://dx.doi.org/10.1007/978-0-387-09608-7

Stricker, L. J., \& Rock, D. A. (1998). Assessing leadership potential with a biographical measure of personality traits. International Journal of Selection and Assessment, 6, 164-184. http://dx.doi.org/10.1111/14682389.00087

Thibaut, J. W., \& Kelley, H. H. (1978). Interpersonal relations: A theory of interdependence. New York, NY: Wiley.

Tichenor, V. (2005). Maintaining men's dominance: Negotiating identity and power when she earns more. Sex Roles, 53, 191-205. http://dx.doi .org/10.1007/s11199-005-5678-2

Wanic, R., \& Kulik, J. (2011). Toward an understanding of gender differences in the impact of marital conflict on health. Sex Roles, 65, 297-312. http://dx.doi.org/10.1007/s11199-011-9968-6

Willoughby, B. J., \& James, S. L. (2017). The marriage paradox. New York, NY: Oxford University Press. http://dx.doi.org/10.1093/acprof: oso/9780190296650.001.0001

Received October 19, 2018 Revision received May 21, 2019 Accepted May 23, 2019 